\title{
Erratum to: Management of Acute Aortic Syndrome and Chronic Aortic Dissection
}

Ian M. Nordon • Robert J. Hinchliffe •

Ian M. Loftus - Robert A. Morgan •

Matt M. Thompson

Published online: 19 January 2012

(C) Springer Science+Business Media, LLC and the Cardiovascular and Interventional Radiological Society of Europe (CIRSE) 2012

Erratum to: Cardiovasc Intervent Radiol

(2011) 34:890-902

DOI 10.1007/s00270-010-0028-3

Figure 4 was published incorrectly. It appears correctly here.
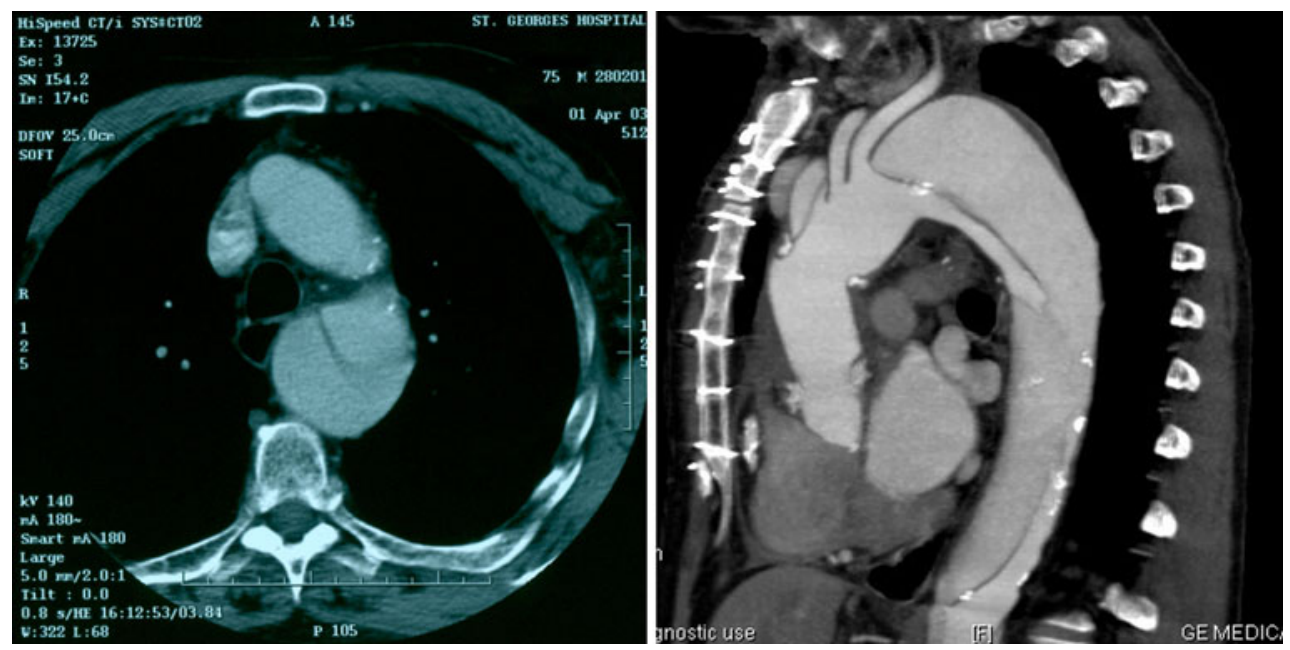

Fig. 4 Axial CT and sagittal reconstruction showing the classic appearance of a type B aortic dissection

The online version of the original article can be found under doi: 10.1007/s00270-010-0028-3.

I. M. Nordon $(\bowtie) \cdot$ R. J. Hinchliffe · I. M. Loftus ·

R. A. Morgan · M. M. Thompson

St. George's Vascular Institute, St. James' Wing, St George's

Hospital, Blackshaw Road, London SW17 0QT, UK

e-mail: inordon@sgul.ac.uk 